\title{
The Combination of Coagulation and Adsorption for Controlling Ultra-Filtration Membrane Fouling in Water Treatment
}

\author{
Fan Bu, Baoyu Gao *(D), Qinyan Yue, Caiyu Liu, Wenyu Wang and Xue Shen \\ Shandong Key Laboratory of Water Pollution Control and Resource Reuse, School of Environmental Science and \\ Engineering, Shandong University, Qingdao 266237, China; bufan1991@163.com (F.B.); \\ qyyue58@aliyun.com (Q.Y.); 17865190108@163.com (C.L.); wenyuwang1992@163.com (W.W.); \\ xueshen_sdu@163.com (X.S.) \\ * Correspondence: baoyugao_sdu@aliyun.com
}

Received: 10 December 2018; Accepted: 3 January 2019; Published: 8 January 2019

\begin{abstract}
Ultra-filtration technology has been increasingly used in drinking water treatment due to improvements in membrane performance and lowering of costs. However, membrane fouling is the main limitation in the application of ultra-filtration technology. In this study, we investigated the impact of four different pre-treatments: Coagulation, adsorption, coagulation followed by adsorption $(\mathrm{C}-\mathrm{A})$, and simultaneous coagulation and adsorption $(\mathrm{C}+\mathrm{A})$, on membrane fouling and natural organic matter removal efficiency. The results showed that adsorption process required a large amount of adsorbent and formed a dense cake layer on the membrane surface leading to severe membrane fouling. Compared to adsorption alone, the coagulation and C-A processes decreased the transmembrane pressure by $4.9 \mathrm{kPa}$. It was due to less accumulation of particles on the membrane surface. As for water quality, the C-A ultra-filtration process achieved the highest removal efficiencies of natural organic matter and disinfection by-product precursors. Therefore, the addition of adsorbent after coagulation is a potentially important approach for alleviating ultra-filtration membrane fouling and enhancing treatment performance.
\end{abstract}

Keywords: water treatment; ultra-filtration; coagulation; adsorption; membrane fouling

\section{Introduction}

Ultra-filtration (UF) has been increasingly used in water treatment because of its high treatment efficiency in terms of particle and microorganism removal [1,2]. As the main limitation to the widespread application of UF, membrane fouling significantly increases the transmembrane pressure (TMP) and reduce membrane life [3]. Several factors, such as formation of filter cake layer, concentration polarization, and membrane pore blocking can destroy the chemical structure of membrane material and lead to membrane fouling [4-6]. Natural organic matter (NOM), including humus and autochthonous biopolymers, is considered to be the main culprit for membrane fouling $[5,7]$. Therefore, many researchers have investigated different types of pre-treatment technologies to remove pollutants from feed water and prevent membrane fouling, such as pre-coagulation, pre-adsorption, pre-filtration, and pre-oxidation [8].

Among these technologies, chemical coagulation has been shown to be an effective and low-cost pre-treatment [9]. Other researchers have found that adsorption is an efficient process for NOM removal and has been adopted as a pre-treatment of UF $[10,11]$. However, the impact of adsorption on membrane fouling is still a controversial topic. Lee et al. [12] found that the dosage of powdered activated carbon (PAC) contributes to the decline of membrane flux. Lin et al. [13] revealed that PAC cannot remove the high molecular weight NOM, which caused the membrane fouling of hydrophobic 
polysulfone membranes. Most researchers agree on the advantages of PAC in adsorbing small molecule NOM components which are hard to remove by coagulation or ultra-filtration. Hence, adsorption is still a process worthy of further study.

Surface water can be effectively cleaned by a pre-treatment-ultra-filtration process. However, NOM is a highly heterogeneous, poorly defined mix of organic substances that vary both spatially and temporally in terms of acidity, molecular weight, molecular structure, and charge density. Coagulation can significantly slow down the decline of UF flux [14,15]. Compared with hydrophilic substance, the hydrophobic substance in NOM can be more efficiently removed by the coagulation process [16]. The hydrophilic substance was found to be the major pollutant responsible for the heaviest flux decline during membrane filtration. The target components in NOM for coagulation and adsorption are significantly different, and the combination of coagulation and adsorption has shown a better performance on NOM removal [17]. Although both coagulation and adsorption have been well investigated as pre-treatments for ultra-filtration, the combination of these technologies, is rarely reported.

Generally, NOM is virtually harmless to humans. However, the NOM in effluent water can easily react with disinfectants and generate miscellaneous toxic and carcinogenic disinfection by-products (DBPs), which have been a focus in drinking water treatment. The commonly identified DBPs in chlorinated drinking water include, trihalomethanes (THMs), haloacetic acids, haloacetonitriles, haloketones, etc $[18,19]$. The DBPs formation is related to the characteristics of organic matters in the effluent of UF. The impacts of pre-treatments on the formation of DBPs after ultra-filtration process are still unknown.

In this research, we built a dynamic pre-treatment, ultra-filtration set-up to treat artificial surface water. Four kinds of pre-treatment were investigated: coagulation (C), adsorption (A), coagulation followed by adsorption (C-A), and simultaneous coagulation and adsorption ( $\mathrm{C}+\mathrm{A})$. In the $\mathrm{C}-\mathrm{A}$ process, the coagulant was firstly added in the rapid mixing unit and then the adsorbent was dosed in the slow mixing unit (a schematic diagram is shown in Figure S1). In the C + A process, the coagulant and adsorbent were simultaneously dosed in the rapid mixing unit such that adsorption and coagulation occurred at the same time. The order of coagulant and adsorbent influences the removal efficiency because the activated carbon may change the adsorption neutralization ability by coagulant. Therefore, the research focused on (1) the NOM removal efficiencies of different pre-treatments and the quality of purified water after ultra-filtration; (2) the impact of different pre-treatments on DBPs formation; (3) the impact of different types of pre-treatments on membrane fouling; (4) the mechanism of membrane fouling during ultra-filtration.

\section{Materials and Methods}

\subsection{Model Water}

The model water for this research was synthesized in order to simulate the surface water and provide a consistent and reproducible sample. Humic acid (HA) (Aladdin, Shanghai, China) was added to the tap water (Jinan, China). The tap water was settled for $24 \mathrm{~h}$ to decay the residual chlorine. The final concentration of the humic acid added was $10 \mathrm{mg} / \mathrm{L}$. Basic water quality parameters of the model water were $\mathrm{pH}=8.3 \pm 0.2$, ultraviolet absorbance at $254 \mathrm{~nm}\left(\mathrm{UV}_{254}\right)=0.231 \pm 0.02 \mathrm{~cm}^{-1}$, dissolved organic carbon $(\mathrm{DOC})=3.947 \pm 0.2 \mathrm{mg} / \mathrm{L}$, and zeta potential $=-17.5 \pm 0.3 \mathrm{mV}$.

\subsection{Coagulant and Adsorbent Preparation}

The coagulant was a combination of polyaluminum chloride (PACl) and polydimethyldiallylammonium chloride (PDMDAAC) which was synthesized in the laboratory. This novel inorganic-organic composite coagulant was shown in previous studies to have a good removal efficiency of organic matter [20-22]. Polyaluminum chloride stock solution was synthesized by adding $22.35 \mathrm{~g}$ of $\mathrm{AlCl}_{3} 6 \mathrm{H}_{2} \mathrm{O}$ and $9.81 \mathrm{~g}$ of $\mathrm{Na}_{2} \mathrm{CO}_{3}$ slowly into $250 \mathrm{~mL}$ deionized water while 
stirring. PACl-PDMDAAC was synthesized by adding $0.62 \mathrm{~g}$ of commercial PDMDAAC (Luyue Shandong Chemical Co., Ltd.) into PACl. Powdered activated carbon (PAC) is a common adsorbent used in drinking water treatment. In this research, the commercial PAC was bought from Far East Chemical Co. Ltd. (Laiyang, China) and was used without further decontamination. PAC was added to reverse osmosis water to make a stock suspension with a concentration of $10.0 \mathrm{~g} / \mathrm{L}$. The nominal properties of PAC are listed in Table S1. During operation of the system, the stock suspension was placed on a magnetic stirring apparatus to maintain steady dispersion.

\subsection{Comparison of the Four Pre-Treatments}

In this research, four kinds of ultra-filtration experiments were performed to investigate the effect of different pre-treatments on the ultra-filtration process.

\subsubsection{Jar Tests}

Jar tests were operated to optimize the dosage of the coagulants and adsorbents. The program was set as follows: Stirring at $200 \mathrm{r} / \mathrm{min}$ was set at fast mixing stage for $1.5 \mathrm{~min}$. After that, $15 \mathrm{~min}$ of slow stirring at $40 \mathrm{r} / \mathrm{min}$ was set to let the flocs grow. Finally, the water was left to stand for $30 \mathrm{~min}$ to settle the flocs. The sample was filtered through a $0.45 \mu \mathrm{m}$ membrane before the quality measurement.

\subsubsection{The Dynamic Ultra-Filtration Processes}

The schematic illustration of the experimental setup is given in Figure S1. The raw water was fed into the system by a constant-level water tank and then flowed into a rapid mixing unit $(200 \mathrm{r} / \mathrm{min}$, $1.5 \mathrm{~min}$ hydraulic retention time (HRT)), a slow mixing unit ( $40 \mathrm{r} / \mathrm{min}, 15 \mathrm{~min}$ HRT), a sedimentation tank (30 min HRT) and then an ultra-filtration tank. The HRT of each unit was designed according to the jar tests. The coagulant was dosed in the rapid mixing unit in the C-UF, C-A-UF and C+A-UF processes. The adsorbent was dosed in the rapid mixing unit in the $\mathrm{C}+\mathrm{A}-\mathrm{UF}$ process and dosed in the slow mixing unit in the C-A-UF process.

Each UF tank had a polyvinylidene fluoride hollow-fiber membrane component. The membrane was purchased from Kunyang Membrane Technology Co. Ltd. (Fujian, China) with a nominal pore size of $30 \mathrm{~nm}$. The pressure transmitter (Sinomeasure Technology Co. Ltd., Hangzhou, China) was connected to the membrane component to continuously record the transmembrane pressure (TMP), which indicated the degree of membrane fouling.

\subsection{Determination of Disinfection By-Products}

The sodium hypochlorite was added to the effluence of ultra-filtration to determine the yield of DBPs. The details of disinfection experiments were conducted as described by Ma et al [23]. To determine the chlorine dosage, a preliminary experiment was performed to provide adequate, free chlorine residual $(2.0 \mathrm{mg} / \mathrm{L}$ as $\mathrm{Cl})$ after $72 \mathrm{~h}$ chlorine disinfection. Residual chlorine concentrations were measured by a Free \& Total chlorine measuring meter (HANNA, Padova, Italy) according to the DPD method (APHA, 2005). The samples used for THMs measurement were dechlorinated by sodium thiosulphate solution.

The yields of dichloroacetonitrile $\left(\mathrm{C}_{2} \mathrm{HCl}_{2} \mathrm{~N}\right)$ and THMs including trichloromethane $\left(\mathrm{CHCl}_{3}\right)$ bromodichloromethane $\left(\mathrm{CHBrCl}_{2}\right)$ dibromochloromethane $\left(\mathrm{CHBr}_{2} \mathrm{Cl}\right)$, and tribromomethane $\left(\mathrm{CHBr}_{3}\right)$ were detected by a gas chromatography, (SHIMADZU Corporation, Kyoto, Japan).

\subsection{Other Analytical Methods}

The fouled membrane samples were taken from the component and observed by scanning electron microscopy (SEM, Hitachi S4800, Tokyo, Japan). In addition, the membrane surface samples were analyzed by attenuated total reflection flourier transformed infrared spectroscopy (ATR-FTIR, NICOLET 5700 FT-IR Spectrometer, Waltham, United States). Particle size distributions of the water 
samples were measured using a laser diffraction particle size analyzer (Mastersizer 2000, Malvern Instruments, Malvern, UK). Zeta potentials were analyzed by Zetasizer Nano (Malvern Instruments, Malvern, UK).

Dissolved organic carbon (DOC) of the samples was analyzed using a Total Organic Carbon Analyzer (Shimadzu, Kyoto, Japan). The UV absorbance at $254 \mathrm{~nm}\left(\mathrm{UV}_{254}\right)$ was determined by a TU-1810 UV/VIS spectrophotometer (Persee, Beijing, China).

\section{Results}

\subsection{Jar Test Results Comparing NOM Removal by Four Different Pre-Treatments}

The removal efficiency of NOM in water was investigated in four kinds of pre-treatments, including coagulation (C), adsorption (A), coagulation followed by adsorption (C-A), and simultaneous coagulation and adsorption $(\mathrm{C}+\mathrm{A})$. The NOM removal efficiencies were represented by the $\mathrm{UV}_{254}$ and DOC values. The $\mathrm{UV}_{254}$ indicates the humic-like substance, which contains conjugated double bonds and benzene rings. The coagulation and adsorption processes were separately optimized based on NOM removal efficiencies and the zeta potential of the coagulant mixture, shown in Figures S2 and S3. At the dosage of $7 \mathrm{mg} / \mathrm{L}$, the $\mathrm{UV}_{254}$ and DOC removal efficiencies were $82 \%$ and $40 \%$ respectively. The zeta potential of the coagulated water was very close to zero at $7.0 \mathrm{mg} / \mathrm{L}$, which means the colloidal system was very easily to aggregate. Hence, the optimum dosage of PACl-PDMDAAC was chosen as $7 \mathrm{mg} / \mathrm{L}$ (as $\mathrm{Al}$ ) for the next experiments. In the adsorption process, the increasing treatment efficiency with the dosage of PAC significantly slowed down when exceeding $400 \mathrm{mg} / \mathrm{L}$. The optimum dosage of PAC was chosen as $400 \mathrm{mg} / \mathrm{L}$. Figure 1 shows the pollutant removal efficiencies by the coagulation-adsorption (C-A) process where PAC was dosed after the coagulation unit. As shown in Figure $1 \mathrm{a}$, with the coagulation process, the highest $\mathrm{UV}_{254}$ removal efficiency was $82.5 \%$ at a dosage of $7.0 \mathrm{mg} / \mathrm{L}$. Therefore, the PACl-PDMDAAC coagulant showed good performance in large organic molecule removal. However, the $\mathrm{UV}_{254}$ removal efficiency did not exceed $85 \%$. As previous researchers have reported, organic matter with low molecular weight is difficult to remove by coagulation [24].

Upon adding the PAC adsorbent, the $\mathrm{UV}_{254}$ removal efficiency significantly increased. Higher PAC dosages led to higher removal rates, and the highest removal rate reached $90 \%$. This indicated that the residual $\mathrm{UV}_{254}$, which cannot be removed by a coagulant, was adsorbed by PAC. However, almost the same $U_{254}$ removal efficiencies were obtained at dosages of $75 \mathrm{mg} / \mathrm{L}$ and $100 \mathrm{mg} / \mathrm{L}$. It indicated that superfluous PAC does not significantly improve $\mathrm{UV}_{254}$ removal.

The DOC removal efficiencies were much lower than the $U_{254}$ removal efficiencies for the four processes (Figure 1b). When dosing coagulant alone, the highest DOC removal efficiency was only $39.8 \%$ with a dosage of $7.0 \mathrm{mg} / \mathrm{L}$. It indicated that more than half of the NOM was not eliminated by coagulation. The SUVA (UV absorbance divided by the DOC concentration) value decreased from $4.94 \mathrm{~L} \cdot \mathrm{mg}^{-1} \cdot \mathrm{m}^{-1}$ to $1.40 \mathrm{~L} \cdot \mathrm{mg}^{-1} \cdot \mathrm{m}^{-1}$ after coagulation, suggesting that the ratio of large organic molecules and the hydrophobic fraction decreased in the effluence of the coagulation unit [25]. However, the hydrophilic substance and organic matter with low molecular weight was difficult to eliminate by coagulation alone.

As we can also see from Figure 1b, PAC significantly enhanced the DOC removal efficiencies of the coagulation process. The same conclusion can be drawn for the $U_{254}$ removal. The increase of dosage led to larger DOC removal efficiency and the highest rate of 55\%. However, there was a large promotion from $75 \mathrm{mg} / \mathrm{L}$ to $100 \mathrm{mg} / \mathrm{L}$, which was different from $\mathrm{UV}_{254}$ removal. In consideration of the economic cost for water treatment, it is impractical to dose over $100 \mathrm{mg} / \mathrm{L}$ of PAC, so we did not increase the dosage of PAC any further in this research. The optimum dosages of coagulant and adsorbent for the C-A process were chosen as: PACl-PDMDAAC $=5 \mathrm{mg} / \mathrm{L}, \mathrm{PAC}=50 \mathrm{mg} / \mathrm{L}$. The relevant $\mathrm{UV}_{254}$ and DOC removal rates were respectively $87 \%$ and $46 \%$. 

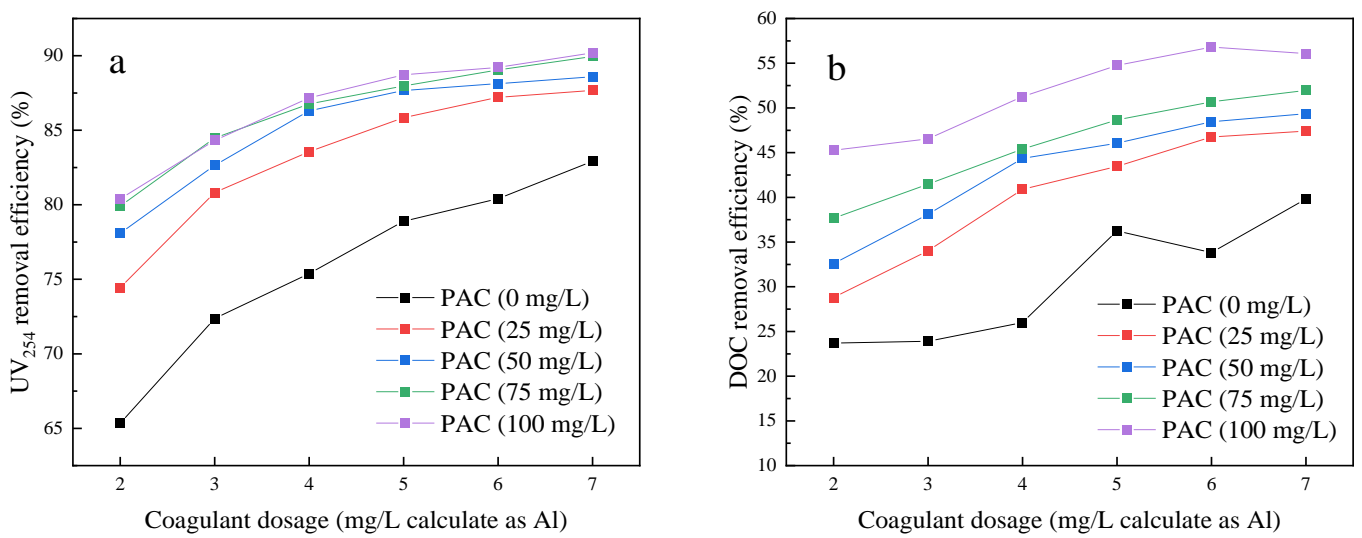

Figure 1. The pollutant removal efficiencies by the coagulation followed by adsorption (C-A) process (a) $\mathrm{UV}_{254}$ removal efficiency (b) Dissolved organic carbon (DOC) removal efficiency.

To test the effects of dosing coagulant and adsorbent at the same time, the pollutant removal efficiencies were measured when both PACl-PDMDAAC coagulant and PAC adsorbent were added to the rapid mixing tank (Figure 2). The highest $\mathrm{UV}_{254}$ and DOC removal efficiencies were obtained when the dosage of PAC was $100 \mathrm{mg} / \mathrm{L}$. Because adsorption occurred in the same tank with coagulation, small molecules and large molecules both had a chance to attach to the surface of PAC and occupy the adsorption sites. Although the PAC demand was higher, the pollutant removal efficiency at the same dosage of coagulant and adsorbent was comparable in both C-A and C + A processes. The $\mathrm{UV}_{254}$ removal rate reached $84 \%$ and the DOC removal rate reached $46 \%$ (which was a virtually good performance) using $5 \mathrm{mg} / \mathrm{L}$ of PACl-PDMDAAC and $75 \mathrm{mg} / \mathrm{L}$ of PAC. These results were slightly higher than the $\mathrm{C}$-A process at the same dosage. To better compare the $\mathrm{C}-\mathrm{A}$ process and the $\mathrm{C}+\mathrm{A}$ process, the same dosage of coagulant and adsorbent were chosen as: PACl-PDMDAAC $=5 \mathrm{mg} / \mathrm{L}$, $\mathrm{PAC}=50 \mathrm{mg} / \mathrm{L}$ for the next experiments.
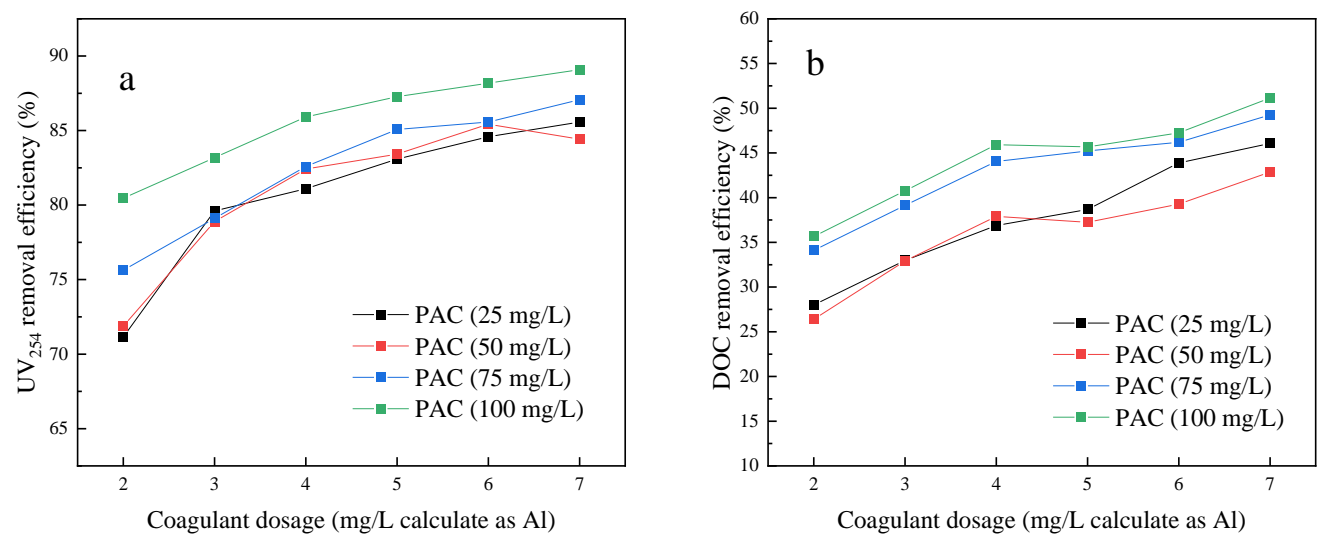

Figure 2. The organic pollutant removal efficiencies by the coagulant and adsorbent $(C+A)$ process (a) $\mathrm{UV}_{254}$ removal efficiency (b) DOC removal efficiency.

\subsection{The Particle Size Distribution in the Effluents of Different Pre-Treatments}

Particle size distribution of the water samples were measured after pre-treatment. The dosages of coagulant and adsorbent were PACl-PDMDAAC $=5 \mathrm{mg} / \mathrm{L}, \mathrm{PAC}=50 \mathrm{mg} / \mathrm{L}$ as determined in Section 3.1. Samples of the supernatant were pumped into the analyzer after the slow mixing stage of the pre-treatment. Figure 3 shows that the median particle diameter in the adsorption effluent was about $20 \mu \mathrm{m}$. The particle size distribution was almost the same for the coagulation alone and $\mathrm{C}+\mathrm{A}$ processes and the median particle diameters were about $400 \mu \mathrm{m}$. The particles were slightly smaller in C-A effluent and the median particle diameters were about $200 \mu \mathrm{m}$. The addition of 
PACl-PDMDAAC led to larger particle sizes and narrower particle size distribution. As a pre-treatment of ultra-filtration, larger particles normally mean less membrane fouling because of the larger space between the particles [26]. However, there is no consensus of opinion on it because of the complexity of raw water and membrane characteristics. Further investigations are made in the following sections.

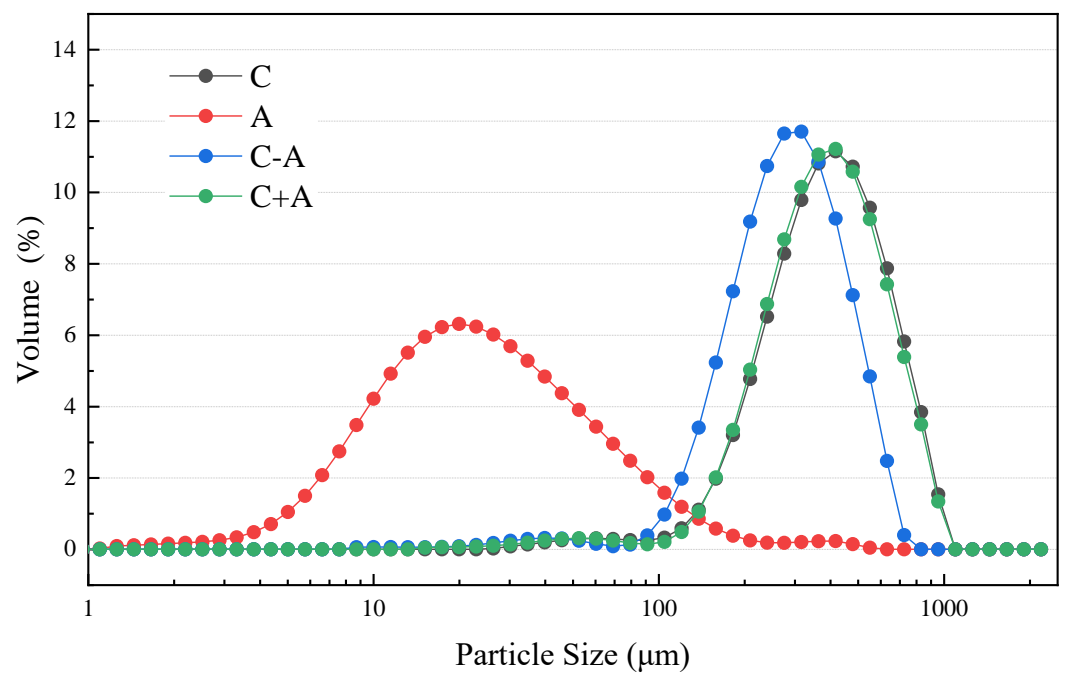

Figure 3. The particle size distribution in the effluents after different pre-treatment jar tests.

\subsection{The Comparison of the Ultra-Filtration Effluents}

The four kinds of pre-treatments were compared in the above sections. In this section, we built a dynamic pre-treatment-ultra-filtration device (Figure S1) to investigate the effect of the pre-treatments on the ultra-filtration process. The dosages of coagulant and adsorbent were determined by Section 3.1.

The $\mathrm{UV}_{254}$ and DOC removal efficiencies of the four combined technologies are shown in Figure 4a. As we can see, all processes had good treatment efficiencies. The DOC removal efficiencies were between $39.5 \%$ and $46 \%$, and the $\mathrm{UV}_{254}$ removal efficiencies were between $83 \%$ and $86 \%$. The residual DOC was lower than $2.0 \mathrm{mg} / \mathrm{L}$ for both four processes. Comparing these processes, the C-A-UF process had the highest $\mathrm{UV}_{254}$ and DOC removal efficiencies. Conventional coagulation achieved $83 \%$ of $\mathrm{UV}_{254}$ removal and 39.5\% DOC removal. The data confirmed that the addition of PAC facilitated effective removal of small molecules, which are difficult to remove by coagulation. However the order of the addition affected the efficiency. At the same dosage of coagulant and adsorbent, the C-A-UF process achieved better $\mathrm{UV}_{254}$ and DOC removal efficiencies than the $\mathrm{C}+\mathrm{A}$-UF process. 



Figure 4. The effect of different pre-treatments for ultra-filtration effluent (a) and transmembrane pressure (TMP) (b).

The evolution of membrane fouling was reflected by the increasing TMP at a constant membrane flux. The comparative increase in TMP for the different processes are shown in Figure $4 \mathrm{~b}$. Compared with filtering raw water, all four pre-treatments reduced the increase of the TMP. The final TMP reached $37 \mathrm{kPa}$ for raw water while it remained less than $25 \mathrm{kPa}$ for the other processes. We conclude that these pre-treatments can help alleviate the membrane fouling. Moreover, the TMP for the four pre-treatments was different. At the end of ultra-filtration $(2500 \mathrm{~min})$, the TMP of the adsorption process was the highest and the TMP of the C+A-UF process was the second highest. These results can be explained by the formation of a dense PAC cake layer. According to Figure 3, the particles in the adsorption process were much smaller than those in the coagulation process. PAC particles easily form a dense cake layer which resists the flow of water. However, the TMP in the C-A-UF process increased slowly despite the presence of PAC. Although the PAC alone may form a dense cake layer, in the presence of the coagulant, it can connect micro flocs by Van der Waals forces to form a porous cake layer $[27,28]$. These two effects balanced and led to a lower TMP.

In the C-A-UF process, TMP reached $20 \mathrm{kPa}$ in the first $500 \mathrm{~min}$, but then remained constant. Although the C-UF process had a lower TMP initially, the same TMP $(20 \mathrm{kPa})$ was observed at the end of the experiment. These results indicate that the addition of PAC can actually reduce the accumulation of particles on the membrane surface. Perhaps because the fiber membrane was arranged vertically under the water, the superfluous cake layer could easily fall off because of gravity. 
Different treatment processes have different target organics to remove. XAD-8 resins fractionate NOM into operationally defined components based on their chemical properties. Figure 5 a shows the classification of NOM components in different treated water, which were separated by XAD-8 resins. The hydrophobic acids (HoAs) and hydrophilic substances (HiS) were dominant in all processes. The proportions of hydrophobic bases (HoBs) and hydrophobic neutrals (HoNs) were lower than the other two fractions in all processes.


Figure 5. Classification of Natural organic matter (NOM) components in raw and treated waters (a), and the concentration of disinfection by-products (DBPs) (b) in treated water.

The C-UF process had the highest proportion of HiS because of the limitation of coagulation for removing small molecules [29]. The A-UF process had the lowest proportion of HiS (32\%), since the HiS were easily adsorbed. HoAs represent a large proportion of organic substances containing humus, protein, and amino acids. Compared to the C-UF process, the addition of PAC decreased the proportion of HiS. In addition, C-A-UF had fewer HiS than C+A-UF, and Figure 4a shows that C-A-UF had a $2.5 \%$ higher DOC removal efficiency than C+A-UF.

The generation of DBPs is a severe problem in drinking water treatment. Figure $5 b$ shows the formation and speciation of halogenated C-DBPs, including trichloromethane $\left(\mathrm{CHCl}_{3}\right)$, dichloroacetonitrile $\left(\mathrm{C}_{2} \mathrm{HCl}_{2} \mathrm{~N}\right)$, bromodichloromethane $\left(\mathrm{CHBrCl}_{2}\right)$, dibromochloromethane $\left(\mathrm{CHBr}_{2} \mathrm{Cl}\right)$, and tribromethane $\left(\mathrm{CHBr}_{3}\right)$ during chlorine disinfection of ultra-filtration effluent. THMs are the most common DBPs in natural water [30]. 
The order of total DBPs yields is C-UF $>$ A-UF $>$ C-A-UF $>$ C+A-UF. These results indicated that the combination of coagulation and adsorption removes more DPB precursors. Previous researchers found that the THM formation is correlated with humic-like substances [31]. Therefore, the higher formation of THMs was possibly attributed to the higher residual humic substances from the separate coagulation and adsorption processes.

Among the four THMs, $\mathrm{CHCl}_{3}$ was the most abundant and the precursor is difficult to remove by coagulation. The concentrations of $\mathrm{CHBrCl}_{2}, \mathrm{CHBr}_{2} \mathrm{Cl}$, and $\mathrm{CHBr}_{3}$ were relatively low. However, it has been reported that bromine containing THMs have much higher cell toxicity even at a low concentration [30]. Therefore, the comparison of the effects of different pre-treatment processes on bromine-containing THMs is also meaningful. The C-A-UF process showed better performance on precursor removal of $\mathrm{CHBrCl}_{2}$ and $\mathrm{CHBr}_{3}$, while the $\mathrm{C}+\mathrm{A}-\mathrm{UF}$ process had better performance on precursor removal of $\mathrm{CHCl}_{3}, \mathrm{C}_{2} \mathrm{HCl}_{2} \mathrm{~N}$, and $\mathrm{CHBr}_{2} \mathrm{Cl}$.

\subsection{Characterization of the Fouled Membrane}

To further investigate the fouling mechanism, Flourier transformed infrared spectroscopy analyses were used on the fouled membrane surface (Figure 6). Attenuated Total Reflection (ATR) spectroscopy is an effective method to characterize chemical composition and surface structure. ATR-FTIR analysis was carried out in this paper on five fouled membranes and new membrane. The spectra are shown in Figure 6 and the spectral analysis is shown in Table 1.

The spectra in Figure 6 show that the PVDF membrane has absorption peaks at 680, 1016, 1380, 1174,1402 and $1720 \mathrm{~cm}^{-1}$ which are the absorption peaks of $\mathrm{CF}_{2}, \mathrm{CH}_{2}$ and $\mathrm{C}=\mathrm{O}$ [32]. The peaks at 1016 and $1720 \mathrm{~cm}^{-1}$ (the gray vertical lines) were reduced for the C-UF membrane because of the organic adsorption. However, these peaks for the A-UF membrane were not reduced obviously and the spectrum was the same as the new membrane. In other words, the absorption process decreased the accumulation of organic matters on the membrane surface.

The spectra of the membrane after the C-A-UF and C+A-UF processes had little difference. Unlike the A-UF spectrogram, the peaks at 1016 and $1720 \mathrm{~cm}^{-1}$ (the gray vertical lines) also obviously decreased. The result can be explained by two reasons: (I) The PAC dosage in these two processes was smaller than in the A-UF process and the organic matter, tightly connected to the membrane, cannot be removed entirely. (II) The chelation of aluminum ion between organic matter and the membrane surface aids the formation of chemical bonds to the membrane.

Table 1. Characteristic infrared (IR) absorption peaks.

\begin{tabular}{cc}
\hline Absorption Peaks $\left(\mathbf{c m}^{-\mathbf{1}}\right)$ & Assignments \\
\hline $830-520$ & F-C-F bending vibration \\
1174 & CF2 stretching vibration \\
$1250-1220,1016$ & C-O stretching vibration \\
1380 & C-H stretching vibration \\
1402 & C-F stretching vibration \\
$1675-1500$ & C=C stretching vibration \\
1720 & C=O stretching vibration \\
\hline
\end{tabular}

The fouled membranes taken from the module were observed by SEM. The images are shown in Figure 7. Homogeneous pores were found on the new membrane surface. After ultra-filtration, cake layers with different topography accumulated at the surface and resisted the flow of water. Figure 7a shows the SEM of the C-UF process membrane where the cake layer is dense. Figure $7 \mathrm{~b}$ shows that there were irregular particles on the membrane surface of A-UF. These accumulations are formed by $\mathrm{PAC}$ and can prevent the residual organic matter from entering the interior of the membrane and clogging the pores. Compared with C+A-UF, the PAC particles are clearly visible in the SEM of C-A-UF because the PAC was added after coagulation (Figure $7 c, d$ ). The relatively sharper PAC particles may increase the water permeability of the cake layer and reduce the TMP (Figure $4 b$ ). 

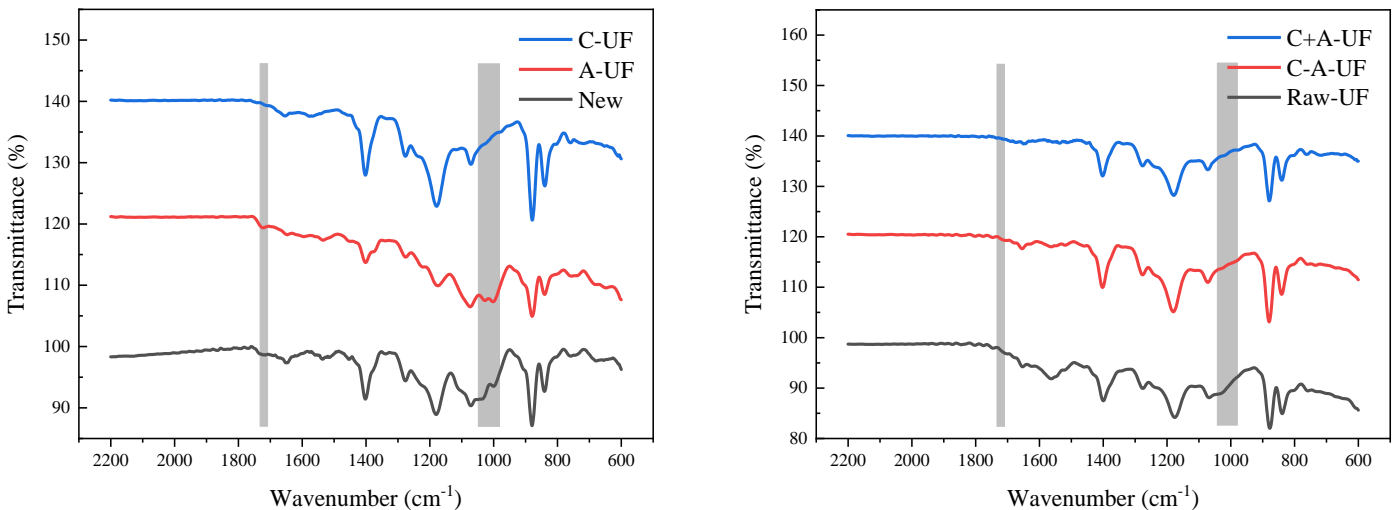

Figure 6. Attenuated total reflection flourier transformed infrared spectroscopy (ATR-FTIR) of the membrane at the end of the experimental period.

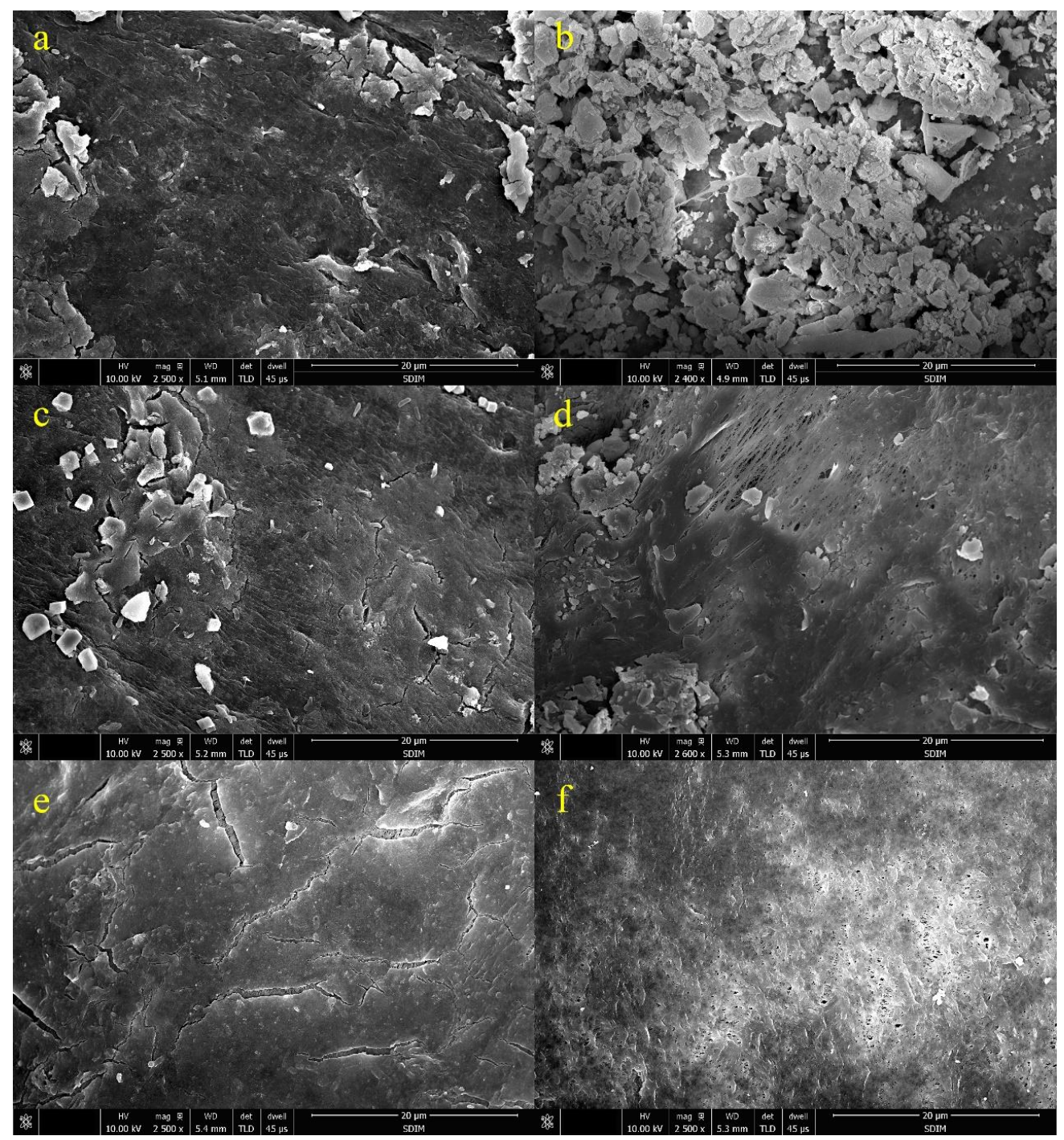

Figure 7. SEM images of membrane surfaces (a) coagulation ultra-filtration (C-UF) (b) adsorption ultra-filtration (A-UF) (c) coagulation ultra-filtration (C-A-UF) (d) coagulation and adsorption ultra-filtration (C+A-UF) (e) ultra-filtration (UF) alone (f) New membrane. 


\section{Conclusions}

This paper presents a novel combination of coagulation and adsorption as pre-treatments for the ultra-filtration process. The impacts of four pre-treatment methods on treatment efficiency and membrane fouling were evaluated.

1. The addition of PAC enhanced the DOC and $\mathrm{UV}_{254}$ removal efficiencies of coagulation. The coagulation followed by adsorption pre-treatment (C-A-UF) process achieved the best water quality of the four processes.

2. The C-A-UF process achieved a higher removal of hydrophilic substances than the C+A-UF process. As for the DBPs, the C-A-UF process showed better performance on the removal of $\mathrm{CHBrCl}_{2}$ and $\mathrm{CHBr}_{3}$, while the $\mathrm{C}+\mathrm{A}-\mathrm{UF}$ process was more effective in the removal of $\mathrm{CHCl}_{3}$, $\mathrm{C}_{2} \mathrm{HCl}_{2} \mathrm{~N}$ and $\mathrm{CHBr}_{2} \mathrm{Cl}$.

3. The TMP of C-UF and C-A-UF were the lowest of all processes. However, the addition of PAC can reduce the accumulation of particles on the membrane surface because PAC removes the organic matter from the filter cake. The C-A-UF process was the best choice for long term operation of ultra-filtration.

Supplementary Materials: The following are available online at http:/ / www.mdpi.com/2073-4441/11/1/90/s1, Table S1: Main properties of PAC, Figure S1: Schematic diagram of ultra-filtration sys, Figure S2: The optimization of the coagulation process, Figure S3: The optimization of the adsorption process.

Author Contributions: Conceptualization, B.G. F.B. and Q.Y.; methodology, F.B. C.L. W.W. and X.S.; investigation, F.B. and C.L.; writing-original draft preparation, F.B. and C.L.; writing-review and editing, W.W. and X.S.; supervision, B.G.; funding acquisition, B.G. All authors approved the final version of the article, including the authorship list.

Funding: This study was supported by the National Natural Science Foundation of China (No. 51678349) and the Tai Shan Scholar Foundation (No. ts201511003).

Acknowledgments: The authors thank Dr. Pamela Holt for editing the manuscript.

Conflicts of Interest: The authors declare no conflict of interest.

\section{References}

1. Boudaud, N.; Machinal, C.; David, F.; Frévalle, B.A.; Jossent, J.; Bakanga, F.; Arnal, C.; Jaffrezic, M.P.; Oberti, S.; Gantzer, C. Removal of $\mathrm{ms} 2, \mathrm{q} \beta$ and ga bacteriophages during drinking water treatment at pilot scale. Water Res. 2012, 46, 2651-2664. [CrossRef] [PubMed]

2. Jacangelo, J.G.; Trussell, R.R.; Watson, M. Role of membrane technology in drinking water treatment in the united states. Desalination 1997, 113, 119-127. [CrossRef]

3. Iritani, E.; Katagiri, N.; Masuda, H. Evaluation of variable pressure dead-end ultrafiltration behaviors of nanocolloids based on filter cake properties. Chem. Eng. Res. Des. 2018, 134, 528-539. [CrossRef]

4. Loginov, M.; Samper, F.; Gésan-Guiziou, G.; Sobisch, T.; Lerche, D.; Vorobiev, E. Centrifugal ultrafiltration for determination of filter cake properties of colloids. J. Membr. Sci. 2017, 536, 59-75. [CrossRef]

5. Sutzkover-Gutman, I.; Hasson, D.; Semiat, R. Humic substances fouling in ultrafiltration processes. Desalination 2010, 261, 218-231. [CrossRef]

6. Al Aani, S.; Wright, C.J.; Hilal, N. Investigation of uf membranes fouling and potentials as pre-treatment step in desalination and surface water applications. Desalination 2018, 432, 115-127. [CrossRef]

7. Amy, G. Fundamental understanding of organic matter fouling of membranes. Desalination 2008, 231, 44-51. [CrossRef]

8. Gao, W.; Liang, H.; Ma, J.; Han, M.; Chen, Z.L.; Han, Z.S.; Li, G.B. Membrane fouling control in ultrafiltration technology for drinking water production: A review. Desalination 2011, 272, 1-8. [CrossRef]

9. Zularisam, A.W.; Ismail, A.F.; Salim, M.R.; Sakinah, M.; Ozaki, H. The effects of natural organic matter (nom) fractions on fouling characteristics and flux recovery of ultrafiltration membranes. Desalination 2007, 212, 191-208. [CrossRef] 
10. Tomaszewska, M.; Mozia, S. Removal of organic matter from water by pac/uf system. Water Res. 2002, 36, 4137-4143. [CrossRef]

11. Stoquart, C.; Servais, P.; Bérubé, P.R.; Barbeau, B. Hybrid membrane processes using activated carbon treatment for drinking water: A review. J. Membr. Sci. 2012, 411-412, 1-12. [CrossRef]

12. Lee, S.J.; Choo, K.H.; Lee, C.H. Conjunctive use of ultrafiltration with powdered activated carbon adsorption for removal of synthetic and natural organic matter. Neuro-Ophthalmology 2000, 6, 357-364.

13. Lin, C.F.; Hao, O.J.; Huang, Y.J. Ultrafiltration processes for removing humic substances: Effect of molecular weight fractions and pac treatment. Water Res. 1999, 33, 1252-1264. [CrossRef]

14. Dong, B.Z.; Wang, H.W.; Feng, J.; Li, W.Y. Influence of coagulation pretreatment on uf membrane flux. Huan Jing Ke Xue 2008, 29, 2783. [PubMed]

15. Yu, W.Z.; Liu, H.J.; Xu, L.; Qu, J.H.; Graham, N. The pre-treatment of submerged ultrafiltration membrane by coagulation-Effect of polyacrylamide as a coagulant aid. J. Membr. Sci. 2013, 446, 50-58. [CrossRef]

16. Korshin, G.; Chow, C.W.K.; Fabris, R.; Drikas, M. Absorbance spectroscopy-based examination of effects of coagulation on the reactivity of fractions of natural organic matter with varying apparent molecular weights. Water Res. 2009, 43, 1541-1548. [CrossRef] [PubMed]

17. Altmann, J.; Zietzschmann, F.; Geiling, E.L.; Ruhl, A.S.; Sperlich, A.; Jekel, M. Impacts of coagulation on the adsorption of organic micropollutants onto powdered activated carbon in treated domestic wastewater. Chemosphere 2015, 125, 198-204. [CrossRef]

18. Zhang, X.; Minear, R.A. Formation, adsorption and separation of high molecular weight disinfection byproducts resulting from chlorination of aquatic humic substances. Water Res. 2006, 40, 221-230. [CrossRef]

19. Jiang, J.; Zhang, X. A smart strategy for controlling disinfection byproducts by reversing the sequence of activated carbon adsorption and chlorine disinfection. Sci. Bull. 2018, 64, 1167-1169. [CrossRef]

20. Li, X.; Zhang, Y.; Zhao, X.; Gao, N.; Fu, T. The characteristics of sludge from enhanced coagulation processes using pac/pdmdaac composite coagulants in treatment of micro-polluted raw water. Sep. Purif. Technol. 2015, 147, 125-131. [CrossRef]

21. Xu, W.; Yue, Q.; Gao, B.; Du, B. Impacts of organic coagulant aid on purification performance and membrane fouling of coagulation/ultrafiltration hybrid process with different al-based coagulants. Desalination 2015, 363, 126-133. [CrossRef]

22. Wang, Y.; Gao, B.; Yue, Q.; Wei, J.; Li, Q. The characterization and flocculation efficiency of composite flocculant iron salts-polydimethyldiallylammonium chloride. Chem. Eng. J. 2008, 142, 175-181. [CrossRef]

23. Ma, D.; Gao, B.; Sun, S.; Wang, Y.; Yue, Q.; Li, Q. Effects of dissolved organic matter size fractions on trihalomethanes formation in mbr effluents during chlorine disinfection. Bioresour. Technol. 2013, 136, 535-541. [CrossRef] [PubMed]

24. Edzwald, J.K. Coagulation in drinking water treatment: Particles, organics and coagulants. Waterence Technol. 1993, 27, 21-35. [CrossRef]

25. Benschoten, J.E.V.; Edzwald, J.K. Chemical aspects of coagulation using aluminum salts-I. Hydrolytic reactions of alum and polyaluminum chloride. Water Res. 1990, 24, 1519-1526. [CrossRef]

26. Li, K.; Liang, H.; Qu, F.; Shao, S.; Yu, H.; Han, Z.S.; Du, X.; Li, G. Control of natural organic matter fouling of ultrafiltration membrane by adsorption pretreatment: Comparison of mesoporous adsorbent resin and powdered activated carbon. J. Membr. Sci. 2014, 471, 94-102. [CrossRef]

27. Kovalova, L.; Knappe, D.R.U.; Lehnberg, K.; Kazner, C.; Hollender, J. Removal of highly polar micropollutants from wastewater by powdered activated carbon. Environ. Sci. Pollut. Res. 2013, 20, 3607-3615. [CrossRef] [PubMed]

28. Gong, H.; Jin, Z.; Wang, Q.; Zuo, J.; Wu, J.; Wang, K. Effects of adsorbent cake layer on membrane fouling during hybrid coagulation/adsorption microfiltration for sewage organic recovery. Chem. Eng. J. 2017, 317, 751-757. [CrossRef]

29. Alexander, J.T.; Hai, F.I.; Al-Aboud, T.M. Chemical coagulation-based processes for trace organic contaminant removal: Current state and future potential. J. Environ. Manag. 2012, 111, 195-207. [CrossRef]

30. Richardson, S.D.; Plewa, M.J.; Wagner, E.D.; Schoeny, R.; Demarini, D.M. Occurrence, genotoxicity, and carcinogenicity of regulated and emerging disinfection by-products in drinking water: A review and roadmap for research. Mutat. Res.-Rev. Mutat. Res. 2007, 636, 178-242. [CrossRef] 
31. Yang, L.; Kim, D.; Uzun, H.; Karanfil, T.; Hur, J. Assessing trihalomethanes (thms) and n-nitrosodimethylamine (ndma) formation potentials in drinking water treatment plants using fluorescence spectroscopy and parallel factor analysis. Chemosphere 2015, 121, 84-91. [CrossRef] [PubMed]

32. Enomoto, S.; Kawai, Y.; Sugita, M. Infrared spectrum of poly(vinylidene fluoride). J. Polym. Sci. Part A Polym. Chem. 2010, 6, 861-869. [CrossRef] 